\title{
Uneven development and the balance of payments constrained model: Terms of trade, economic cycles, and productivity catching-up
}

\author{
Danilo Spinola \\ United Nations University - Maastricht Economic and Social Research Institute on Innovation and Technology (UNU-Merit), Boschstraat 24, 6211 AX \\ Maastricht, The Netherlands
}

\section{A R T I C L E I N F O}

\section{Article history:}

Received 12 August 2019

Revised 31 March 2020

Accepted 7 May 2020

Available online 28 May 2020

\begin{tabular}{l}
\hline JEL: \\
E22 \\
E32 \\
O41
\end{tabular}

Keywords:

Balance of payments constraints

Terms of trade

Economic cycles

Latin American structuralism

\begin{abstract}
A B S T R A C T
This paper addresses (I) the transition dynamics incompatibility between the BPCM and the PrebischSinger hypothesis (PSH) (II) the causes of cyclical volatility in developing countries. In order to discuss these issues, we expand the Dutt (2002) model adding: (a) a productivity gap dynamics in which the south has a catching-up element; (b) a labor market dynamics, by including a wage curve in the relationship between employment rate and economic activity; and (c) a labor supply dynamics that considers the labor transfer issue between traditional and modern sectors. The result is a four dimensional dynamic model that represents a lagged developing economy constrained by its balance of payments. We find that our model converges and generates damped cycles. Fragile economies show an oscillatory decline in terms of trade, reinforcing an uneven development pattern between north and south. Industrialization and higher learning capabilities, however, can change the adjustment to a catching-up scenario.
\end{abstract}

(C) 2020 The Author. Published by Elsevier B.V. This is an open access article under the CC BY license. (http://creativecommons.org/licenses/by/4.0/)

\section{Introduction}

Thirlwall's framework, also known as the Balance of Payments Constrained Model (BPCM), is one of the most relevant contributions of the Post-Keynesian school of thought to economic theory (Davidson, 1990). It states that the equilibrium growth rate of an economic system must be compatible with the constraints imposed by the balance of payments. Assuming that terms of trade and financial flows are stable in the long run, Thirlwall derives a rule in which the growth rate of an economy depends directly on the ratio of the income elasticity of demand between exports and imports, times foreign growth. This became known in the literature as the Thirlwall Law (Mccombie, 1989).

There is a large literature tradition focused on estimating the parameter of the Thirlwall Law, measuring the income elasticity of demand for imports and exports to different countries (see reviews by Blecker, 2016 and McCombie, 2012). The literature shows that the Thirlwall law offers a good proxy to explain long-run growth rates for developed countries. In developing economies, however, the correlation between observed growth rates and the ones predicted by the BPCM are not that strong
(Alonso \& Garcimartín, 1998). Short-term effects of terms of trade fluctuation and financial flows volatility systematically deviate the actual growth rates from the one predicted by the law (Thirlwall \& Hussain, 1982).

The strict focus on the Thirlwall law relegates important aspects of the BPCM such as uneven development and the short- to longrun transition dynamics to the background (Dutt, 2002). In this research we focus the analysis on these two relevant aspects.

A central assumption of the Thirlwall law is that the long run prices are neutral and do not affect long run economic growth. This assumption is subject to critiques - as described by McCombie (2012). It is not compatible with the core of the Structuralist tradition, condensed in the Prebisch-Singer Hypothesis (PSH), which states the existence of a declining long-run trend in the terms of trade for developing countries (Harvey et al., 2010). This trend is caused by a specialization of the productive structure in products with smaller income elasticity of demand (primary commodities). As income grows, the relative prices of primary commodities increase at a smaller rate than manufactured goods, resulting in a long run decline in the terms of trade (Prebisch, 1950). This reinforces the uneven development conditions between north and south.

E-mail addresses: sartorello@merit.unu.edu, danilospin@hotmail.com 
In addition, we bring the discussion of the transition dynamics, relating the short-run volatility to the long run equilibrium growth rate. In the short-run, both price and quantity effects serve as adjustment mechanisms: price- and income-elasticity of imports and exports; the terms of trade; as well as financial flows adjust the economy to the equilibrium. Dutt (2002) offers a possible solution to the transition dynamics between short- to long-run, starting from the explicit equations for imports and exports, matter also debated by Blecker (2016) and Razmi (2016). The Dutt model endogenizes the evolution of the terms of trade towards the long-run adjustment. It consists in a north-south dynamic model in which the north follows a monopolistic Keynesian-Kaleckian framework while the south is modelled in perfect competition with a MarxLewis perspective.

In addition to the BPCM-PSH debate, another source of uneven development in the short run is related to economic volatility. Countries with larger GDP volatility, usually developing countries, face higher challenges in achieving a stable development process (Szirmai, 2015). Regular patterns of volatility may emerge in the transitory dynamics between short- and long-run. A canonic contribution remotes to the Goodwin (1967) model, discussing the emergence of cycles from the relationship between economic activity and income distribution.

The Goodwin model was initially thought for a closed economy. To discuss it as an open economy, we consider it in the context of the balance of payments constrained model, as discussed by the recent contributions of Nishi (2019) and Dávila-Fernández \& Sordi (2019).

In order to discuss the long run properties of the model, we debate the role of the productive structure. Since Prebisch (1950), the behavior of the terms of trade has been defined by the productive structure of a country in the context of an international division of labor. A specialized structure with smaller labor productivity level shows a higher productivity gap between the laggard south and the advanced north. This impacts in a decline in the terms of trade, as the southern economy is specialized in products with smaller income elasticity of demand, which reduces its growth possibilities (Cimoli \& Porcile, 2010). On the other hand, the productivity gap follows its own dynamics. Laggard economies may have higher opportunities for learning, approaching the productivity levels of the north. The evolutionary catching-up literature is central in this regard (Silverberg \& Verspagen, 2003; Verspagen, 1992), as technology and productivity gap may create catching-up opportunities for developing economies (Lee, 2013) if these countries manage to develop their absorptive capacity.

The objective of this research is to understand the transition dynamics in the BPCM, using a north-south framework. Terms of trade adjustments occur in the presence of economic cycles and productivity gap. We initially follow the baseline model defined by Dutt (2002) and expand it by: (a) adding a productivity gap dynamics in which the south has a catching-up element (Fu, Pietrobelli, \& Soete, 2011; Verspagen, 1992); (b) model the labor market of the southern economy by including a wage curve (Bhaduri \& Marglin, 1990; Blanchflower \& Oswald, 1994), showing the cyclical relationship between employment rate and economic activity; (c) add a labor supply dynamics that considers the Lewisian problem of the labor transfer between traditional and modern sectors (Lewis, 1954). The inclusion of these elements changes the structure of the Dutt model, resulting in a four dimensional expanded dynamic system able to generate interesting patterns in the trajectory between short- and long-run. We study the stability conditions of the model and present some possible scenarios.

After this introduction, Section 2 develops the literature review. Section 3 raises the research questions. Section 4 consists of the expansions to the Dutt (2002) model. Section 5 discusses the properties of the expanded model, developing the baseline and scenar- ios. Section 6 discussed the main results. Finally, Section 7 concludes this paper.

\section{Literature review}

\subsection{Thirlwall's law and the Thirlwall model}

The BPCM (Thirlwall, 1979; Thirlwall \& Hussain, 1982) is a growth model that links the economic growth possibilities with the constraints imposed by the balance of payments. The model can be explicitly derived from the import $(M)$ and export $(X)$ functions:

$M=\theta_{M}(1 / P)^{-\mu} Y^{\varepsilon}$

$X=\theta_{X}(P)^{-v} Y_{f}^{\delta}$

$\theta_{M}$ and $\theta_{X}$ are constants. $Y$ is the domestic income and $Y_{f}$ the foreign income. The relative price $P$ represents the price ratio between domestic prices $\left(P_{d}\right)$ and foreign prices $\left(P_{f}\right)$, in domestic currency - multiplied by the nominal exchange rate $(E)$, in which $P=P_{d} / E P_{f} . \mu$ and $v$ are the price elasticities of imports and exports, respectively. Finally, $\varepsilon$ and $\delta$ are the income elasticity of imports and exports. Imports increase with higher domestic income while exports grow with higher foreign income. Import falls with increases in the relative price $^{1}(P)$ while exports rise. The equilibrium of the balance-of-payments occurs when total exports plus net financial flows $(F)$ match total imports:

$P X+F=M$

Writing Eq. (3) in terms of growth rates we have:

$[1-(F / M)][\hat{P}+\hat{X}]+(F / M) \hat{F}=\hat{M}$

When replacing $\hat{M}$ and $\hat{X}$ by the growth rates of Eqs. (1) and (2), we end up with the Thirlwall growth equation (Thirlwall \& Hussain, 1982), which can be written as:

$\hat{Y}=(1 / \varepsilon)\left\{(1-\mu-v) \hat{P}+[1-(F / M)] \delta \widehat{Y}_{f}+\left(F / X_{N}\right)[\hat{F}-(1-v) \hat{P}]\right\}$

In the long-run, Thirlwall considers price-neutrality: growth of terms of trade $(\hat{P}=0)$, and capital flows are constant $(\hat{F}=0)$. These assumptions result in the Thirlwall law, in which the equilibrium growth rate depends on the ratio between income elasticities of demand for exports and imports; multiplied by the rate of growth of foreign GDP:

$\hat{Y}=(\delta / \varepsilon) \widehat{Y}_{f}$

Income growth rate then depends on the income elasticities, which are exogenous ${ }^{2}$.

The usual simplification $(\hat{P}=\hat{F}=0)$ results in some theoretical and empirical problems: (1)The simplification ignores the transitional dynamics, as pointed out by Dutt (2002). We cannot observe the adjustment between short- and long-run, which neglects some possible effects in the dynamic process that affect the final outcomes. (2) There is a high number of articles reviewed by Blecker (2016) and McCombie (2012), questioning the empirical validity of the Thirlwall law, especially for developing regions, as the observed long-run growth rate diverges from the income elasticity ratio times foreign income. (3) The BPCM assumes that terms of

\footnotetext{
1 Following Dutt (2002), the nominal exchange rate $(E)$ is considered as a numerary $(E=1)$, then $P=P_{d} / P_{f}$

2 There are some articles focused on endogenizingthe income elasticities in the Structuralist theory, relating income elasticities to the behavior of the productive structure and technological change such as Cimoli \& Porcile (2014); and Porcile \& Spinola (2018).
} 
trade do not affect the long-run, which goes in contradiction with the decline in the terms of trade theory $(\hat{P}<0)$ (Prebisch, 1950). In this paper we focus on the dynamics of the terms of trade, leaving the matter of financial flow dynamics to a future debate ${ }^{3}$.

\subsection{Uneven development and the transitional dynamics}

The questions posed in this research concern the dynamics between the "short-run" version of the BPCM and its "long-run" version, which results in the Thirlwall law. Dutt (2002) proposes a transition dynamics in an open economy north-south framework, focusing on uneven development, an important but less debated ${ }^{4}$ matter in the BPCM framework.

Uneven development is a central aspect to understand the behavior of developing economies (Szirmai, 2015). This discussion contraposes itself to the Solow-type neoclassical growth models, and approaches itself to the Structuralist ideas of Prebisch and Singer (Dutt, 2019), where the position of an economy in the international division of labor defines its development possibilities. A country specialized in the production and export of low-tech raw materials tends to progressively lag behind than those that produce and export high-tech manufactured goods (Prebisch, 1950). Products are heterogeneous in terms of their price and income elasticity of demand. Products with higher income elasticity of demands (manufactured goods) relatively increase their demand as international economy grows, resulting in higher relative prices. The result is the emergence of an uneven development in which the core countries of the system advance in their productive structure while the periphery remains trapped in lower levels of economic development (Lavopa \& Szirmai, 2018).

The Thirlwall framework does not focus directly on productive heterogeneity. However, it discusses the role of income elasticity of demand for imports and exports, which can be linked to the evolution of the productive structure (Cimoli \& Porcile, 2014; Porcile \& Spinola, 2018). In the canonical BPCM there is no inherent terms of trade decline trend as in the Structuralist tradition, a problem that has been discussed in the literature by authors such as Dutt (2002), Razmi (2016), and Blecker (2016).

\subsection{Assumptions and challenges of the Thirlwall law}

The canonic BPCM (Thirlwall, 1979; Thirlwall \& Hussain, 1982) depends on key assumptions to keep its validity. Blecker (2016) highlights the question of price neutrality, in which price effects do not affect the long-run equilibrium growth rate. This question assumes that price-elasticity is very low (elasticity pessimism: $\mu+v \approx 1$ ), that the real exchange rate grows at zero rate in the long run $(\hat{P}=0)$ and that financial flows balance itself to zero growth $(\hat{F}=0)$. Economic adjustments to the equilibrium then occur in quantities rather than prices, and the domestic growth rate adjusts the system to the conditions imposed by the balance of payments constraints.

In the new Structuralist tradition (Cimoli, Lima, \& Porcile, 2016; Porcile \& Yajima, 2019), the theories by Prebisch and Thirlwall are usually seen as complementary. However, the price dynamics is a source of theoretical contradiction usually neglected in the discussion. In the theory of decline in the terms of trade - the PrebischSinger hypothesis (PSH) - there is a long-run tendency to decline in prices $(\hat{P}<0)$. When accepting the PSH and that the MarshallLerner condition holds (price elasticity imports is bigger than 1 ), price effects are not neutral in the long-run, and terms of trade

\footnotetext{
3 Thirlwall \& Hussain (1982) first introduced capital flows in the BPCM for developing countries. This literature was later developed by the works of McCombie \& Thirlwall (1997) and Moreno-Brid (2003).

4 This topic was firstly introduced by McCombie \& Thirlwall (1994).
}

decline in developing countries. This perspective is not compatible with the assumptions that lead to the Thirlwall Law.

In the PSH, price-effects play a central role in defining the longrun economic growth rate. However, the PSH is a non-convergent model, in which there is no convergence of prices to a steady state, but a secular decline, in which a developing southern economy is trapped in a lower development stage.

\subsection{The Thirlwall-Goodwin tradition - volatility in the BPCM}

Economic volatility is an important element that creates constraints to economic development (Szirmai, 2015). By understanding the roots of volatility in developing countries we deal with an important development matter that halts long-run development strategies. This paper brings the growth model tradition started by Goodwin (1967), who developed a closed economy system in which economic activity and income distribution runs in a cyclical predator-prey dynamics.

Reconciling the BPCM with an open version of the Goodwin system would allow us to capture the relationship between foreign constraints and issues generated by volatility in the economic system. In the literature, Pugno (1998) was the first author to investigate the relationship between income distribution and external constraint. More recently, authors such as Nishi (2019) and DávilaFernández \& Sordi (2019) made important contributions to the literature connecting the BPCM with the Goodwin model, in which cycles oscillate around the long-run equilibrium balance of payments constrained growth rate.

Our approach aims to reconcile Thirlwall and Goodwin in the same direction as the above mentioned contributions, including the relationship between income distribution and unemployment rate/economic activity to the BPCM framework. We define a wage curve (Blanchflower \& Oswald, 1994), a modified version of the Phillips Curve, generating a labor market dynamics in the BPCM expansion of Dutt (2002).

\subsection{The Structuralist Thirlwall tradition - Productive structure and technology gap in the BPCM}

Finally, an important debate in the New Structuralism relates the BPCM to the productive structure of developing systems. In a recent strand of the Structuralist literature, learning and structural change are brought to the model by endogenizing income elasticities of imports and exports (Cimoli \& Porcile, 2014; Porcile \& Spinola, 2018). Structural transformation and technological change alter the productive structure, affecting the income elasticity ratio, increasing the equilibrium rate of growth. These contributions consider the price-neutrality assumption, and long-run economic growth adjusts to the structural conditions of the economy.

The productive structure dynamics in a north-south BPCM literature considers a productivity/technology gap dynamics in an Evolutionary approach. Laggard economies in the south have potentially higher learning opportunities, approaching the productivity levels of the north (Fu et al., 2011; Lee, 2013). This gap may create development opportunities. However, as highlighted by Verspagen (1992), the learning process is not automatic. The laggard economy needs to develop internal conditions, such as learning capabilities and absorptive capacity, allowing it to absorb foreign technology and foster productivity catching-up.

Our contribution to the literature links the emerging ThirlwallGoodwin tradition to elements of the productive structure, drawing from the Evolutionary theory, which has at its main pillar the classic work of Schumpeter (1939) about economic cycles.

The introduction of endogenous technical change into the context of distributive models was initially done by Shah and Desai (1981), and further elaborated by Van der Ploeg (1987), 
Foley (2003), and Tavani \& Zamparelli (2017). Specially in what concerns the literature on evolutionary economics, the distributive cycle model is the starting point for an investigation on the dynamics of innovation creation and diffusion in Englmann (1994), Fatás-Villafranca, Jarne, \& Sánchez-Chóliz(2012), and Dosi, Sodini, \& Virgillito (2015).

\section{Research considerations and the baseline Dutt (2002) model}

This research proposes to conciliate the BPCM with the PSH in an open economy growth model, relating (1) the dynamic behavior of the terms of trade with (2) cyclical volatility, and (3) the productive structure through the discussion of the productivity gap. It consists in a Structuralist Thirlwall-Goodwin model in the same tradition as Dávila-Fernández \& Sordi (2019), adding evolutionary elements, such as productivity/technological gap.

The seminal Dutt (2002) model offers a starting point to answer our research questions. It criticizes the Thirlwall Law offering a theoretical alternative, inside the BPCM framework, to challenge the idea that prices are neutral in the long-run. This model allows us to approach the Prebisch-Singer hypothesis (PSH) to the context of the BPCM, observing transition dynamics and uneven development. As mentioned in the literature review, the literature has advanced with the works of Razmi (2016), and Blecker (2016).

The Dutt original model focuses on how terms of trade evolves from capital accumulation. Our contribution adds elements that deal with the matter of volatility to that model, debating its main determinants. Following a Structuralist perspective (Cimoli et al., 2016), we associate the regular volatility to the fragile structural conditions of developing economies, adding an element of productivity gap. We link three central structural issues of developing economies: balance of payments constraints, high growth volatility, and fragile productive structures.

Our central discussion focuses on how price dynamics affect the results of the BPCM when assuming Pendogenous, and if we can observe Prebisch-Singer $(\hat{P}<0)$. We analyze how technology efforts and structural change are related to price effects and debate the catching-up process, discussing how countries away from the technological frontier show themselves as more fragile and volatile.

\subsection{The Dutt (2002) model}

The canonical Dutt (2002) model discusses two economies that interact through their external sector: (i) a southern economy, marked by perfect competition with fixed real wage and unemployment labor (following a Marx-Lewisian structure), and (ii) a northern economy that has imperfect competition, in which firms practice mark-up pricing and excess capacity, with a KaleckiKeynesian structure. The derivation of the model can be found in the annex of this paper.

Terms of trade dynamics follow the relationship between capital accumulation in the north and the south:

$\hat{P}=\left[1 /\left(\mu_{N}+\mu_{S}-1\right)\right]\left(\varepsilon_{N} g_{N}-\varepsilon_{S} g_{S}\right)$

Which means that terms of trade $(P)$ will fluctuate depending on the gap between investment (per unit of capital) in the north $\left(g_{N}\right)$ and the south $\left(g_{S}\right)$, weighted by their respective income elasticity of demand for imports $\left(\varepsilon_{N}\right.$ and $\left.\varepsilon_{S}\right)$, and by price elasticities $\left(\mu_{N}\right.$ and $\mu_{S}$ ).

\section{Dutt-Thirlwall expansion model}

The original Dutt model results in a one moving equation for the dynamics of the terms of trade. In this expansion we focus on adding a productivity gap dynamics, including a wage curve, and modelling a labor supply dynamics.

\subsection{Productivity dynamics}

Following a Kalecki-Keynesian structure, the northern price levels are defined as function of mark-up $(z)$ over costs, given by the product between northern nominal wages $\left(W_{N}\right)$ and the fixed unitlabor requirement $\left(b_{N}\right): P_{N}=(1+z) W_{N} b_{N}$. We initially introduce a dynamics for labor productivity $\left(\lambda_{N}=1 / b_{n}\right)$ and for the wage rate in the north:

$\widehat{b_{N}}=-\beta_{N}$

$\widehat{W_{N}}=\beta_{N}$

$\beta_{N}$ is a constant. Labour productivity in the north $\left(\lambda_{N}\right)$ grows exogenously, and wages track productivity, growing both at the same rate $\left(\widehat{\lambda_{N}}=\beta_{N}\right)$. In this sense, productivity and real wages follow the same path, growing according to an exogenous technological progress. Technological progress in the north is assumed constant and stable ${ }^{5}$.

The south has a constant capital-output ratio, with no idle capacity: $Y_{S}=K_{S} / a_{S}$. Real wages $\left(V_{S}\right)$ are defined as $V_{S}=W_{S} / P_{S}$. The share of southern profits in total income $\left(\sigma_{S}\right)$ is given by $\sigma_{S}=\left(1-b_{S} V_{S}\right)$; capitalist's income $\left(Y_{S, K}\right)$ in the south is equal to $Y_{S, K}=\left(1-b_{S} V_{S}\right) P_{S} Y_{S}$. We the need to specify $b_{s} V_{s}$, so they stay within bounds, as the wage share cannot be smaller than zero or higher than one.

As above mentioned, labor productivity $\left(\lambda_{i}\right)$ is the inverse of the unit labor requirement for the production of a good:

$\lambda_{i}=\frac{1}{b_{i}}$

Using this definition, the productivity gap $(G)$ between north and south is:

$G=\ln \left(\frac{\lambda_{N}}{\lambda_{S}}\right)=\ln \left(\frac{b_{S}}{b_{N}}\right)$

Productivity grows in the north at a constant rate $\widehat{\lambda_{N}}=\beta_{N}$. In the south we consider a gap effect, caused by the laggard characteristics of the southern economy. We then endogenize the southern fixed-unit labor requirement $\left(b_{s}\right)$ and the real wages $\left(V_{s}\right)$. Labor productivity dynamics in the south is an autonomous constant rate $\left(\beta_{S}\right)$ plus the effect of the productivity gap, which depends on a catching-up effect $(\rho)$ :

$\widehat{\lambda_{S}}=\beta_{S}+\rho G$

The catching-up effect is not automatic, but depends on learning efforts and on the absorptive capacity of the economy (Verspagen, 1992). As the north grows at an autonomous higher technological rate $\left(\beta_{S}<\beta_{N}\right)$, we can work out the dynamics of the technology gap $(\hat{G})$ as:

$\hat{G}=\left(\beta_{N}-\beta_{S}\right)-\rho G$

\subsection{Labor market and the wage curve}

A second addition to the model includes a labor market dynamics. We add a wage curve for the southern economy, a modified version of the famous Phillips curve, relating real wages to the employment rate $^{6}$ (Blanchflower \& Oswald, 1994):

$\widehat{V_{S}}=-m+n\left(\frac{L_{S}}{\Lambda_{S}}\right)=-m+n l_{S}$

\footnotetext{
${ }^{5}$ We understand, on the other hand, the central aspect of evolutionary major technological change happening in waves (Schumpeter, 1939).

6 We would like to reinforce that this expanded model deals with a modified version of the Phillips curve, from which a Goodwin dynamics emerge from the own characteristics of the model, and how prices are defined, maintaining the classic idea that economic activity and income distribution interact generating cycles.
} 
The parameters $m$ and $n$ are constants. $L_{S}$ consists on total employment, and $\Lambda_{S}$ is the total workforce. Employment rate $\left(l_{S}\right)$ can be defined as a ratio between total employment $\left(L_{S}\right)$ and total workforce $\left(\Lambda_{S}\right)$ :

$l_{s}=\frac{L_{S}}{\Lambda_{S}}$

This addition changes the characteristics of the model. The southern profit share $\sigma_{S}=\left(1-b_{S} V_{S}\right)$ is no longer a constant. Being the southern wage $\left(\omega_{S}\right)$ equal to $\omega_{S}=b_{S} V_{S}$, in growth rates:

$\widehat{\omega_{S}}=\widehat{b_{S}}+\widehat{V_{S}}=-\beta_{S}-\rho G-m+n l_{S}$

The growth rate of the profit share in the south $\left(\sigma_{S}\right)$ follows the opposite variation of the wage share $\left(\omega_{\mathrm{S}}\right)$ :

$\widehat{\sigma_{S}}=-\widehat{\omega_{S}}=\beta_{S}+\rho G+m-n l_{S}$

A moving profit share changes the southern investment by unit of capital $\left(g_{S}\right)$ as $g_{S}=I_{S} / K_{S}$. Southern investment depends on savings: $I_{S}=P^{\xi} S_{S}$. Savings $\left(S_{S}\right)$ are the share of total income related to profits, as only capitalists save in the south: $S_{S}=s_{S} \sigma_{S} K_{S} / a_{S}$. In this case, $\sigma_{S}$ becomes a variable, and $g_{S}$ is not a constant anymore, affecting the whole dynamics of the terms of trade.

In the north, investments are an independent function, depending on capacity utilization $(u)$, caused by effective demand. Being $\gamma_{0}$ and $\gamma_{1}$ constants, then $g_{N}=\gamma_{0}+\gamma_{1} u$. Expanding $u$ (annex), then $g_{N}=\gamma_{0}\left(1+\frac{\gamma_{1}}{s_{N} \sigma_{N}-\gamma_{1}}\right)$.

Expanding $g_{N}$ and $g_{S}$ result in the following equation for the evolution of the terms of trade:

$\hat{P}=\frac{1}{\mu_{N}+\mu_{S}-1}\left[\varepsilon_{N} \gamma_{0}\left(1+\frac{\gamma_{1}}{s_{N} \sigma_{N}-\gamma_{1}}\right)-\varepsilon_{S} \frac{s_{S} P^{\xi} \sigma_{S}}{a_{S}}\right]$

\subsection{Employment rate, population growth and the Lewis dynamics}

In terms of labor supply, we may consider two different situations that lead to the same result. The first is an economy divided by traditional and modern sectors. A higher share of total income going to labor creates incentives for workers move to formal activities of the economy (Lavopa \& Szirmai, 2018). The second situation is related to migration. A higher incentive may lead workers to move from one country to the other, increasing the labor supply in the receiver country (Sabot, 2019).

Considering a linear specification relating the increases in wage share (and reduction in profit share) to the southern labor supply $\left(\Lambda_{S}\right)$, then:

$\widehat{\Lambda_{S}}=\varphi-\psi \sigma_{S}$

$\varphi$ is the constant autonomous population growth and $\psi$ is a constant that measures the elasticity to move to from the traditional to the modern sector (or the migration cost). As $l_{S}=L_{S} / \Lambda_{S}$, in growth rates $\widehat{l_{S}}=\widehat{L_{S}}-\widehat{\Lambda_{S}}$. Considering $b_{S}=\frac{L_{S}}{Y_{S}}$, in growth rates $\widehat{L_{S}}=$ $\widehat{b_{S}}+\widehat{Y}_{S}$, and the employment rate dynamics is defined as:

$\widehat{l_{S}}=\widehat{b_{S}}+\widehat{Y}_{S}-\widehat{\Lambda_{S}}$

We have that $Y_{S}=K_{S} / a_{S}$. As there is no depreciation, therefore investment and capital accumulation are exactly equal $\widehat{K}_{S} K_{S}=$ $I_{S}$. From the Savings-Investment southern condition $\left(I_{S}=P^{\xi} S_{S}\right)$ and being $S_{S}=s_{S} \sigma_{S} Y_{S}$, then $I_{S}=P^{\xi} s_{S} \sigma_{S} \frac{K_{S}}{a_{S}}$. Capital accumulation in the south is, as previously discussed:

$\widehat{K}_{S}=\frac{I_{S}}{K_{S}}=P^{\xi} s_{S} \sigma_{S} \frac{1}{a_{S}}$

As southern capital-output ratio is constant $\left(\widehat{a_{S}}=0\right)$, then $\widehat{K}_{S}=$ $\widehat{Y}_{S}$. Finally the dynamic equation for the southern employment rate is given by:

$\widehat{l_{S}}=-\beta_{S}-\rho G+P^{\xi} s_{S} \sigma_{S} \frac{1}{a_{S}}-\varphi+\psi \sigma_{S}$
The expansions result in a system of four differential equations:

$\hat{P}=\frac{1}{\mu_{N}+\mu_{S}-1}\left[\varepsilon_{N} \gamma_{0}\left(1+\frac{\gamma_{1}}{s_{N} \sigma_{N}-\gamma_{1}}\right)-\varepsilon_{S} \frac{s_{S} P^{\xi} \sigma_{S}}{a_{S}}\right]$
$\widehat{\sigma_{S}}=\beta_{S}+\rho G+m-n l_{S}$
$\widehat{l_{S}}=-\beta_{S}-\rho G+P \xi S_{S} \sigma_{S} \frac{1}{a_{S}}-\varphi+\psi \sigma_{S}$
$\hat{G}=\left(\beta_{N}-\beta_{S}\right)-\rho G$

This system defines the north-south dynamics between terms of trade, distribution in the south, southern employment rate and the productivity gap. The adjustment defines the transition dynamics between the short- and the long-run in the model.

\section{Dynamic properties of the expanded model}

From the four equations of our system we calculate the steady state and the Jacobian, studying the equilibrium and the stability conditions.

Initially, we calculate the steady state setting the dynamic variables equal to zero. $\hat{P}=\widehat{\sigma_{S}}=\widehat{l_{S}}=\hat{G}=0$. Then we calculate the Jacobian $(J)$ at the steady state, a matrix of the partial derivatives of all pair of dynamic variables involved in the system. We study the signs of the elements of the Jacobian in the Annex 2.

The steady state conditions are:

$P^{*}=\left[\frac{\gamma_{0} a_{S} \psi}{\left[\varphi+\beta_{N}-\frac{\varepsilon_{N} \gamma_{0}}{\varepsilon_{S}}\left(1+\frac{\gamma_{1}}{s_{N} \sigma_{N}-\gamma_{1}}\right)\right]} \frac{\varepsilon_{N}}{\varepsilon_{S} s_{S}}\left(1+\frac{\gamma_{1}}{s_{N} \sigma_{N}-\gamma_{1}}\right)\right]^{1 / \xi}$

$\sigma_{S}^{*}=\frac{1}{\psi}\left[\varphi+\beta_{N}-\frac{\varepsilon_{N} \gamma_{0}}{\varepsilon_{S}}\left(1+\frac{\gamma_{1}}{s_{N} \sigma_{N}-\gamma_{1}}\right)\right]$

$l_{S}^{*}=\frac{1}{n}\left(\beta_{N}+m\right)$

$G^{*}=\frac{\left(\beta_{N}-\beta_{S}\right)}{\rho}$

The matrix of partial derivatives of the system results in Jacobian of the model. Considering the row/column order as $P, \sigma_{S}, l_{S}$, and $G$ :

$J=\left[\begin{array}{cccc}-\frac{1}{\mu_{N}+\mu_{S}-1} \frac{\varepsilon_{S} s_{S} \sigma_{S}}{a_{S}} \xi P^{\xi-1} & -\frac{1}{\mu_{N}+\mu_{S}-1} \frac{\varepsilon_{S} S_{S} P^{\xi}}{a_{S}} & 0 & 0 \\ 0 & 0 & -n & \rho \\ \xi P^{\xi-1} S_{S} \sigma_{S} \frac{1}{a_{S}} & P^{\xi} S_{S} \frac{1}{a_{S}}-\psi & 0 & -\rho \\ 0 & 0 & 0 & -\rho\end{array}\right]$

In order to analytically observe stability we use the theorems presented by Gandolfo (1971) and Liu, Shen, Cai, \& Yan (2018):

Theorem 1. Stability criterion: if the eigenvalues of the Jacobian matrix of a dynamical system all have negative real part at the equilibrium point, the point is asymptotically stable. Because it is very hard to calculate the eigenvalues, we use the Routh Hurwitz criteria to study the stability conditions of the model.

Theorem 2. Routh-Hurwitz criterion: the eigenvalues of $J$ have negative real part if and only if all of the coefficients of the characteristic polynomial of $J$ and all leading principal minors of the Hurwitz matrix corresponding to the characteristic polynomial are positive.

From Annex 2 we have the signs of the Jacobian.

$\operatorname{Sign}(\mathrm{J})=\left[\begin{array}{cccc}- & - & 0 & 0 \\ 0 & 0 & - & + \\ + & + & 0 & - \\ 0 & 0 & 0 & -\end{array}\right]$ 
Assuming $J$ as:

$(\mathrm{J})=\left[\begin{array}{llll}a & b & 0 & 0 \\ 0 & 0 & g & h \\ i & j & g & h \\ 0 & 0 & 0 & p\end{array}\right]$

If we define $t$ as the eigenvalue of the Jacobian; the characteristic polynomial of $J$ is

$$
\begin{gathered}
\Pi(t)=t^{4}+(-a-p) t^{3}+(a p-j g) t^{2} \\
+(a j g+j g p-b g i) t+(\text { bgip }- \text { ajgp })
\end{gathered}
$$

The coefficients are: $\alpha_{0}=1 ; \alpha_{1}=-a-p ; \alpha_{2}=a p-j g ; \alpha_{3}=$ $a j g+j g p-b g i$

$\alpha_{4}=$ bgip - ajgp

The stability condition states that all coefficients of $\Pi(t)$ must be positive. Studying the signs of the Jacobian, the only necessary condition for all values be positive is $b i>a j$, which results, after substituting the values, in the final condition that $\psi>0$, already considered in our analysis.

In order to calculate the leading principal minors, we construct the Hurwitz matrix:

$$
H=\left[\begin{array}{ccccc}
\alpha_{1} & \alpha_{0} & 0 & 0 & 0 \\
\alpha_{3} & \alpha_{2} & \alpha_{1} & \alpha_{0} & 0 \\
0 & \alpha_{4} & \alpha_{3} & \alpha_{2} & 0 \\
0 & 0 & 0 & \alpha_{4} & \alpha_{1} \\
0 & 0 & 0 & 0 & \alpha_{3}
\end{array}\right]
$$

Then we calculate the determinants for the associate matrices of $H: \Delta_{1}=\left|\alpha_{1}\right| ; \Delta_{2}=\left|\begin{array}{cc}\alpha_{1} & \alpha_{0} \\ \alpha_{3} & \alpha_{2}\end{array}\right| ; \Delta_{3}=\left|\begin{array}{ccc}\alpha_{1} & \alpha_{0} & 0 \\ \alpha_{3} & \alpha_{2} & \alpha_{1} \\ 0 & 0 & \alpha_{3}\end{array}\right|$; the same for $\Delta_{4}$ and $\Delta_{5}$. All determinants show to be positive under the conditions imposed in Annex 2, which analytically explains that our model is stable.

It is possible to observe the presence of cycles as the RouthHurwitz criterion gives us the necessary conditions to the occurrence of a Poincaré-Andronov-Hopf bifurcation (Gandolfo, 1971):

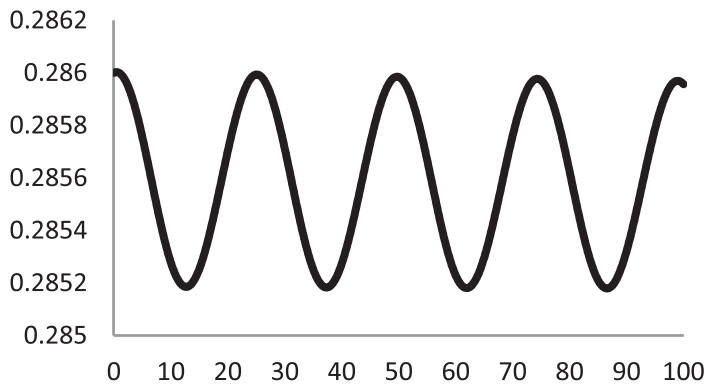

$\longrightarrow$ Terms of Trade

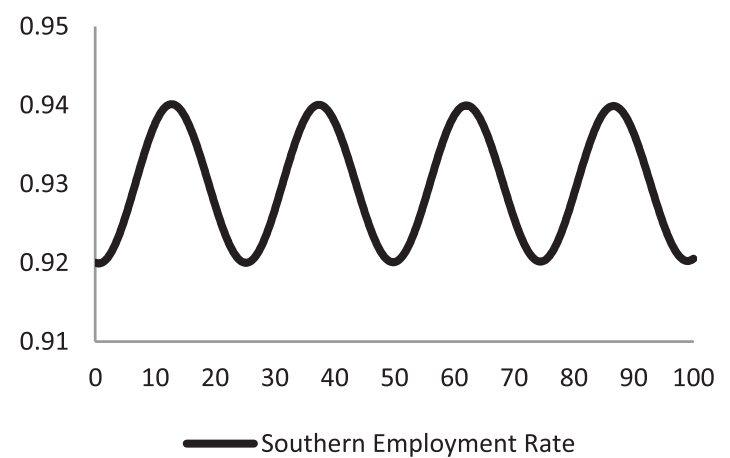

Theorem 3. Limit cycle criterion: if the eigenvalues of the Jacobian matrix have all negative real parts except a pair of conjugate imaginary values, there is a limit cycle. If all the eigenvalues are negative and we see the presence of a pair of conjugate imaginary values, then the model present damped cycles, adjusting to the equilibrium.

In terms of the Routh Hurwitz condition test to the presence of limit cycle (Gandolfo, 1971): if all the Hurwitz determinants are positive, we calculate the Sturm series $\left(\Phi_{i}\right)$ associated to the characteristic polynomial, and check the values of its coefficients. Being $k$ the degree of the polynomial; and $i$ in $[1 ; k]$, then:

$\Phi_{i}(\mu)=c_{i, 0} \mu^{k-1}+c_{i, 1} \mu^{k-i-2}+c_{i, 2} \mu^{k-i-4}+\ldots$

For a characteristic polynomial of degree 4 , if we have $c_{4,0}=0$ and $c_{3,1}<0$ then all the eigenvalues of the associated Jacobian have negative real parts, except a purely imaginary conjugate pair. However, this is not observed in the analysis. The Dutt expansion does not show a limit cycle, but is able to reproduce dampened cycles.

In the next session we present a baseline and some scenarios that illustrate the behavior of the system. The values are defined in our calibration procedure at Annex 3. From there we analyze the eigenvalues to define the pattern of transition dynamics.

\subsection{Baseline}

Based on the values discussed on Annex 3, the baseline model is built as an exercise to find credible parameters values for a developing economy (south) and for a developed country (north). The developing economy is marked by a low industrialization, with capital-output ratio $\left(a_{S}\right)$ close to 3 . It follows the MarshallLerner condition $\left(\mu_{N}+\mu_{S}>1\right)$. Autonomous technological growth is higher in the north than in the south $\left(\beta_{N}>\beta_{S}\right)$ with the south catching up at the rate $\rho$. Savings rate in the north $\left(s_{N}\right)$ is around $35 \%$ while in the south $\left(s_{S}\right)$ it is around $18 \%$. Initial value for the profit rate in the south $\left(\sigma_{S}\right)$ is $30 \%$, being $40 \%$ in the north $\left(\sigma_{N}\right)$. Southern exogenous increase in labor force $(\varphi)$ is about $4 \%$ while
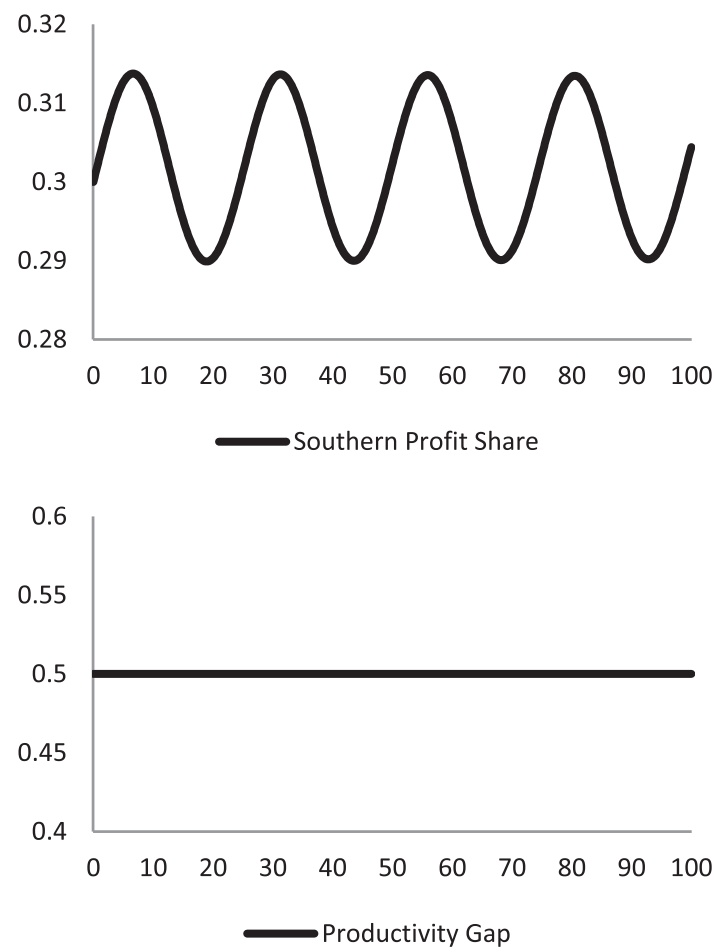

Fig. 1. Baseline results. 
Table 1

Baseline model parameter values.

\begin{tabular}{llll}
\hline$a_{s}=3$ & $\varepsilon_{N}=1.05$ & $m=0.9$ & $\rho=0.3$ \\
$\xi=0.5$ & $S_{N}=0.35$ & $n=1$ & $\varphi=0.04$. \\
$\mu_{N}=1$ & $s_{S}=0.18$ & $\sigma_{N}=0.4$ & $\psi=0.2$ \\
$\mu_{S}=1$ & $\gamma_{0}=0.005$ & $\beta_{S}=0.005$ & \\
$\varepsilon_{S}=0.95$ & $\gamma_{1}=0.06$ & $\beta_{N}=0.03$ & \\
initial values & & & \\
$P_{0}=0.286$ & $\sigma_{S 0}=0.3$ & $l_{S 0}=0.92$ & $G_{0}=0.5$ \\
\hline
\end{tabular}

Table 2

Baseline: steady state and eigenvalues.

\begin{tabular}{lllr}
\hline Steady State & $P^{*}=0.285 \quad \sigma_{S}^{*}=0.301$ & $l_{S}^{*}=0.929$ & $G^{*}=0.5$ \\
Eigenvalues & $e_{1}=-0.0003+0.255 \mathrm{i}$ & $e_{2}=-0.0003-0.255 \mathrm{i}$ \\
& $e_{3}=-0.0250+0.000 \mathrm{i}$ & $e_{4}=-0.0039+0.000 \mathrm{i}$ \\
\hline
\end{tabular}

the country shows higher labor force elasticity to increases in the wage share $(\psi)$. With the initial southern employment rate $\left(l_{S}\right)$ of $92 \%$, the parameters used for our baseline are the following:

The baseline results show a situation in which the technology gap is constant at its initial level of 0.5 . Terms of trade oscillate around a stable trend. Southern profit shares oscillate between the values of $29 \%$ and $31 \%$. And the employment rate is between $92 \%$ and $93.5 \%$. We observe the presence of cycles, as there is a pair of conjugate complex eigenvalues. The model converges, as there are negative real values to the eigenvalues. We see that the convergence takes many time periods to occur.

\subsection{Scenario 1: Declining terms of trade in a lagging behind scenario}

From the baseline calibration we define a case in which the economy is under a more fragile situation. It consists in a less industrialized economy (smaller $a_{s}$ ), in which the learning process occurs at a slower pace (reduced $\rho$ ) and the autonomous productivity growth is smaller (reduction in $\beta_{S}$ ). It is also an economy in which there is a smaller elasticity to move from the traditional to the modern sector $(\varphi)$.
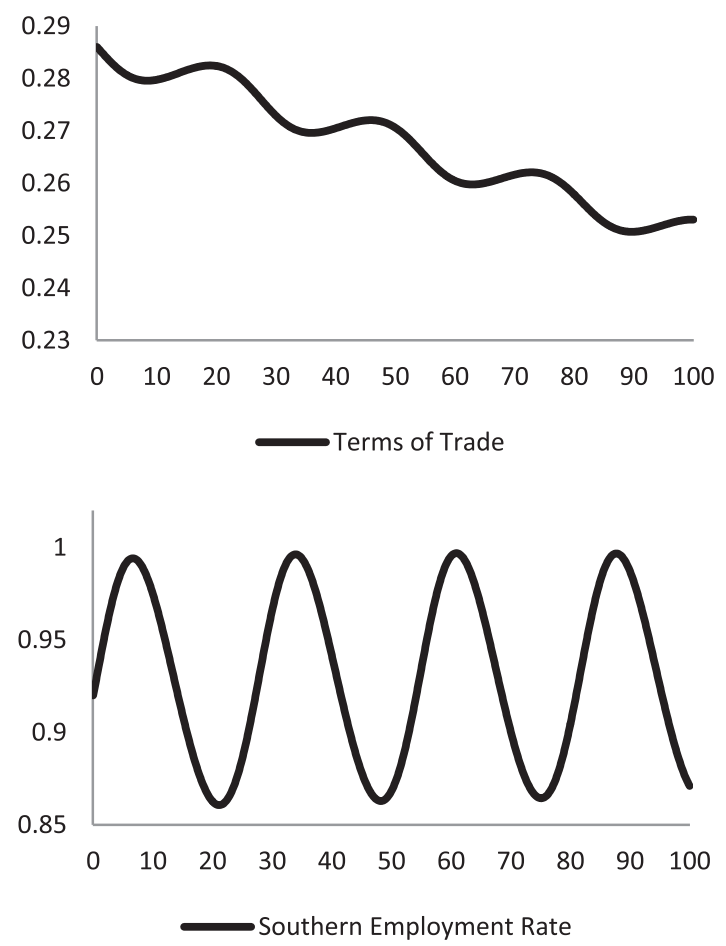

Table 3

Values for the lagging behind case (scenario 1).

\begin{tabular}{lll}
\hline initial values & & \\
$\begin{array}{l}P_{0}=0.286 \quad \sigma_{S 0}=0.3 \\
\text { modified values }\end{array}$ & $l_{S 0}=0.92$ & $G_{0}=0.5$ \\
$a_{s}=2 \quad \beta_{S}=0.001$ & $\rho=0.05$ & $\varphi=0.03$ \\
\hline
\end{tabular}

Table 4

Scenario 1: steady state and eigenvalues.

\begin{tabular}{llll}
\hline Steady State & $P^{*}=0.182$ & $\sigma_{S}^{*}=0.251$ & $l_{S}^{*}=0.930 \quad G^{*}=0.58$ \\
Eigenvalues & $e_{1}=-0.0003+0.236 \mathrm{i}$ & $e_{2}=-0.0003-0.236 \mathrm{i}$ \\
& $e_{3}=-0.0290+0.000 \mathrm{i}$ & $e_{4}=-0.0038+0.000 \mathrm{i}$ \\
\hline
\end{tabular}

The structure of a less industrialized and more fragile economy specializes in the exports of products with smaller technology intensiveness, such as primary commodities (Cimoli \& Porcile, 2014). In this economy there are limited learning capacity and the regressive structural change moves towards sectors with smaller productivity (Lavopa \& Szirmai, 2018). The results can be seen on Figure 2. This more fragile economy reaches the equilibrium at a higher productive gap compared to the baseline model.

The Prebish-Singer hypothesis (PSH) can be discussed in this scenario. The southern, peripheral country shows a decline in its terms of trade. However, this decline follows a cyclical adjustment toward a new equilibrium value $\left(P^{*}=0.182\right)$ reached after many time periods. Unlike the non-convergent pattern of the $\mathrm{PSH}$, the model is stable, reaching steady state at a certain point, as we have negative real part for all eigenvalues. Capital accumulation and domestic growth would follow the same trajectory as the terms of trade $\left(\hat{Y}_{S}=g_{S}=\overline{s_{S}} P^{\xi} \sigma_{S} / \overline{a_{S}}\right)$, showing a reduction in the growth rate. In the steady state we see a small increase in unemployment and a smaller profit share when compared to the baseline.

This more fragile economy has higher volatility. When calculating the standard deviations of the baseline we have that $S D_{b}(P)=0.0002 S D_{b}\left(l_{s}\right)=0.007$ and $S D_{b}\left(\sigma_{s}\right)=0.008$. For scenario $1, S D_{S 1}(P)=0.01 ; S D_{S 1}\left(l_{S}\right)=0.048$ and $S D_{S 1}\left(\sigma_{S}\right)=0.046$, increasing the amplitude of the oscillations.
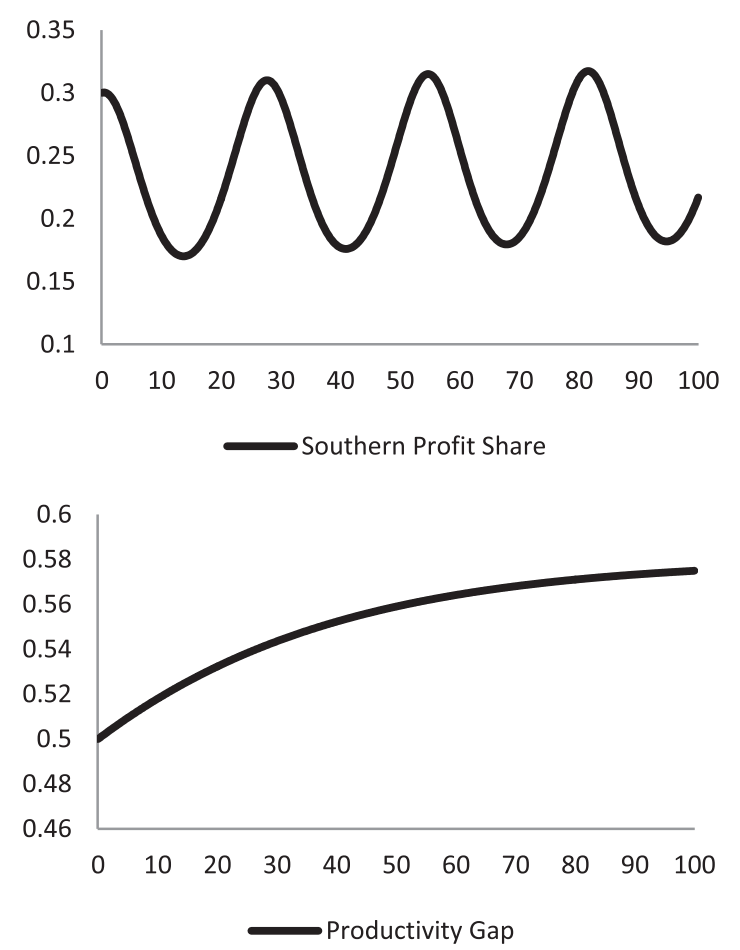

Fig. 2. Results for Scenario 1. 

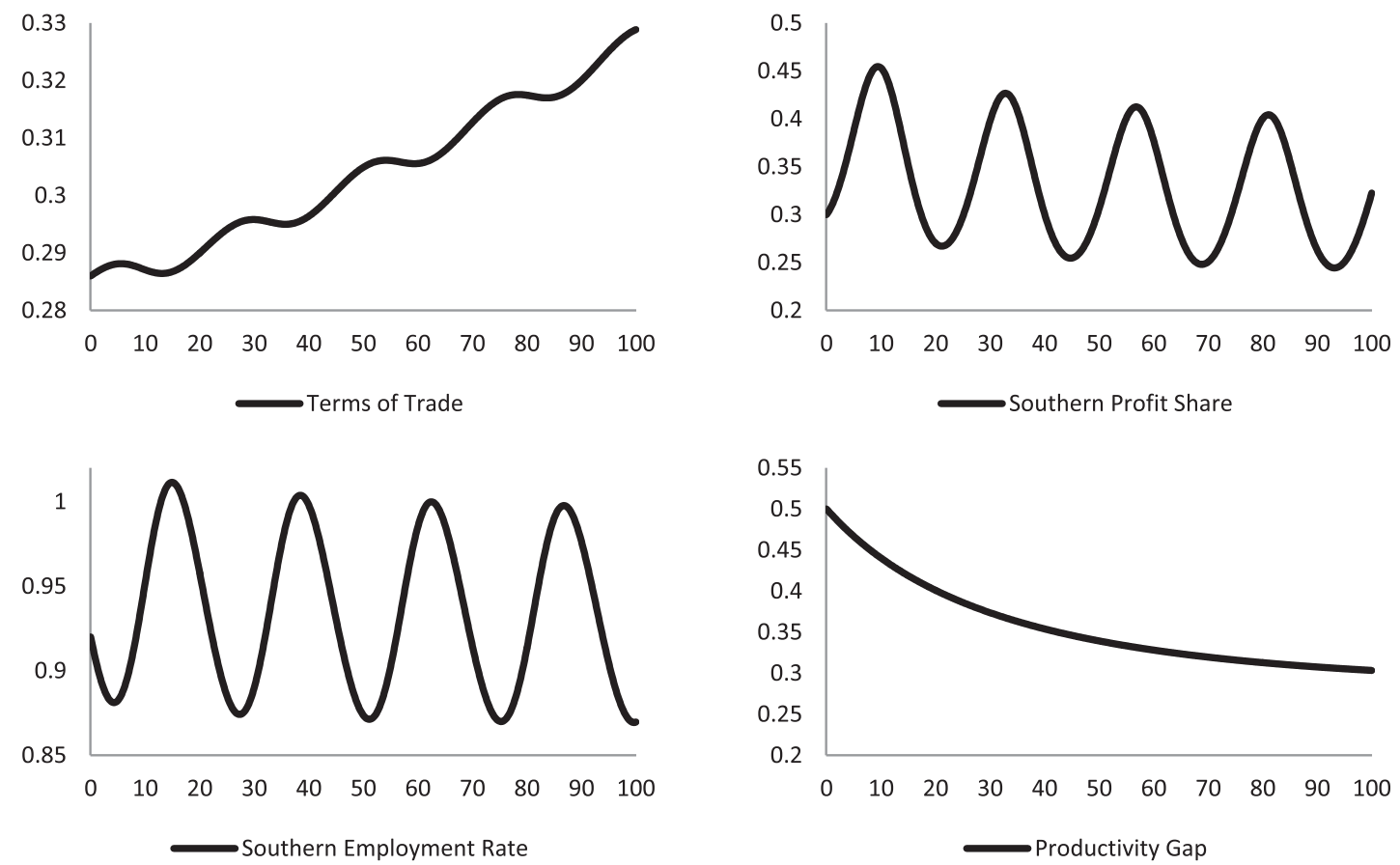

Table 5

Fig. 3. Results for Scenario 2.

Values for the catching-up case (scenario 2).

\begin{tabular}{lcc}
\hline initial values & & \\
$P_{0}=0.286 \quad \sigma_{S 0}=0.3$ & $l_{S 0}=0.92$ & $G_{0}=0.5$ \\
modified values & & \\
$a_{S}=4 \quad \beta_{S}=0.01$ & $\rho=0.07$ & $\varphi=0.04$ \\
\hline
\end{tabular}

Table 6

Scenario 2: steady State and eigenvalues.

\begin{tabular}{|c|c|c|c|}
\hline Steady State & $P^{*}=0.507$ & $\sigma_{S}^{*}=0.301 l_{S}^{*}=0.930$ & $G^{*}=0.28$ \\
\hline Eigenvalues & $\begin{array}{l}e_{1}=-0.0003+0.255 \mathrm{i} \\
e_{3}=-0.020+0.000 \mathrm{i}\end{array}$ & $\begin{array}{l}e_{2}=-0.0003-0.255 \mathrm{i} \\
e_{4}=-0.003+0.000 \mathrm{i}\end{array}$ & \\
\hline
\end{tabular}

\subsection{Scenario 2: Increases in the terms of trade and catching-up}

In this scenario we emulate an economy which, starting from the baseline, focus on two main aspects: structural change (industrialization) and learning capabilities, generating a technological catching-up pattern. In this scenario we increase the capitaloutput ratio, the exogenous productivity rate, the catching-up parameter and the rate to which workers from the traditional sector move to the modern one.

Scenario 2 shows the opposite situation compared to scenario 1. The southern economy reduces the productivity gap with the north. There is economic diversification, and a structural change towards more productive sector. In this scenario, the country reverses the tendency to reduce its terms of trade, generating an increase in its growth rate. This growth and structural change process creates higher volatility compared to a stagnated baseline, as $S D_{S 2}(P)=0.012 ; S D_{s 2}\left(\sigma_{S}\right)=0.061$, and $S D_{S 2}\left(l_{S}\right)=0.046$.

\section{Discussion of the results}

The price dynamics directly affect the behavior of the effective economic growth (the one observed in the short-run), as we have: $\hat{Y}_{S}=g_{S}=\overline{s_{S}} P \xi \sigma_{S} / \overline{a_{S}}$. The effective growth rate will then depend on the dynamic behavior of prices $(P)$ (terms of trade/real exchange rate) and income distribution $\left(\sigma_{S}\right)$.

A decline in the terms of trade can be observed under the condition $\varepsilon_{S} \frac{s_{S} P^{\xi} \sigma_{S}}{a_{S}}>\varepsilon_{N} \gamma_{0}\left(1+\frac{\gamma_{1}}{s_{N} \sigma_{N}-\gamma_{1}}\right)$. We showed that the model converges. In this sense, despite the fall in the terms of trade, the explosive behavior of the PSH is not valid to the long-run. An alternative to reconcile it with the BPCM is to accept the existence of a medium-run in the transition dynamics. The PSH declines in a medium-run in which the BPCM is not price-neutral, offering an adjustment mechanism that explains the decline in the terms of trade in the context of balance of payments constrained growth.

Considering the northern characteristics as fixed, we see that a decrease in industrialization (reduction of $a_{S}$ ), a decline in the wage share (rise in $\sigma_{S}$ ), a rise in the propensity to save $\left(s_{S}\right)$ and a rise in the income elasticity of imports $\left(\varepsilon_{S}\right)$ - reducing productive capacity and specialization, result in a decreasing trend in the terms of trade and a smaller economic growth.

A southern country has to advance with structural change and increase learning capacity to avoid following a decline in its terms of trade. Specialization in low technology intensive sectors and a lack of learning opportunities will result in a decline in terms of trade (and economic growth). In terms of technology efforts this is an indirect effect, as the technology gap $(G)$ does not directly affect terms of trade $(P)$, but employment $\left(l_{S}\right)$ and income distribution $\left(\sigma_{S}\right)$. Increases in the technology gap reduce the growth rate of the employment rate, but increases the growth rate of the profit rate.

According to Goodwin, cycles emerge from the relationship between economic activity and income distribution ${ }^{7}$. Volatility exists in all studied cases, as we can see from the baseline model. We observe that both a catching-up and a falling behind pattern raise volatility compared to the initial stable condition. Volatility increases when the absolute values of $\frac{\partial \hat{\sigma}_{S}}{\partial l_{S}}$ and $\frac{\partial \hat{l}_{S}}{\partial \sigma_{S}}$ increase without changing their sign. As $\frac{\partial \hat{l}_{S}}{\partial \sigma_{S}}=-n$ and $n>0$, when $n$ increases we observe more intense oscillations. The same is valid when $\frac{\partial \hat{\sigma}_{S}}{\partial l_{S}}=P^{\xi} s_{S} \frac{1}{a_{S}}-\psi$ increases its value - as $P^{\xi} s_{S} \frac{1}{a_{S}}>\psi$. In this sense, industrialization reduces volatility (rise in $a_{S}$ ), and the elasticity between employment rate and wages $(\psi)$. Increases in the

7 Our model presents dampened cycles, in a similar result as the works of La Marca (2010) and Barbosa-Filho \& Taylor (2006). Despite the absence of a limit cycle in the model expansion, the characteristics of the relationship between economic activity and income distribution maintain the model as part of the openeconomy Goodwin tradition. 
autonomous propensity to save increases volatility as well as economic growth (rise in the terms of trade). We observe that growth brings an increase in volatility, but it can be compensated by a virtuous structural change towards more productive sectors.

Higher long-run growth happens when $P$ increase its value, so the south can grow at a higher rate than the predicted in the BPCM. This increasing adjustment in terms of trade happens in a scenario in which a virtuous structural change, learning opportunities and higher quality in the employment are a priority in the economic development of an economy.

We fixed the income elasticity ratio, observing the effects of productivity on prices. However, it is important to mention that catching up and productivity growth also affects the productive structure through changes in income elasticities, moving the ${ }^{\varepsilon_{N}} / \varepsilon_{S}$ ratio (Cimoli \& Porcile, 2014; Porcile \& Spinola, 2018). An exogenous change in the income elasticity ratio has a similar effect as changes in $a_{S}$, which can be observed by looking at the dynamic of terms of trade $\hat{P}$ and of its steady state $P^{*}$. Future expansion of this model could add an endogenous income elasticity of demand for imports and exports, generating a different dynamics to the system.

\section{Conclusion}

Dutt (2002), in a critique to an excessive focus of the literature on the Thirlwall law, highlighted some other central aspects of the Thirlwall framework: uneven development and the transition dynamics between short- to long-run. The author endogenizes, from a north-south model, the behavior of the terms of trade in a Balance of Payments Constrained Model (BPCM) framework.

This research expands the Dutt (2002) model by adding a Goodwin cyclical dynamics with a wage curve; a lewisian labor market transition between traditional and modern sectors; and a productivity/ technological catching-up dynamics for the southern economy in relationship to the northern one. In this sense we extend to the BPCM a Post-Keynesian distributive dynamics and a Structuralist-Evolutionary aspect of structural change and technological catching-up.

The model we present converges to the steady state, maintaining, in the long-run, the price neutrality argument $(\hat{P}=0)$. We show that the transition to the long-run is not direct, and may involve distinct types of dynamics. In an addition to the monotonic convergence of the Dutt model, our model reproduces damped cycles, with terms of trade and economic growth cyclically converging in the long-run. The addition of a productivity dynamics and a specific labor market structure contributes to the expansion of the Thirlwall-Goodwin tradition of Nishi (2019) and Dávila-Fernández \& Sordi (2019). In this research, we observe new types of transition dynamics under dynamic prices in the BPCM (Dutt, 2002); offering an alternative to expand the cyclical discussion in the New Structuralist tradition of Cimoli \& Porcile (2014) and Porcile \& Yajima (2019). In this sense, this article adds new elements to the emerging literature on open economy Goodwin models and on the Structuralist BPCM.

From the model baseline and scenarios, increases in industrialization and learning efforts generate a pattern with higher growth, increases in the terms of trade, and reduction in the technology gap. A virtuous catching-up strategy raises volatility when compared to a stagnated economy, this rise in volatility is also present when observed the case of a falling behind scenario.

Growth reduces or increases in the long run depending on the functional income distribution and on the terms of trade, both depending also on technology catching-up and on the employment rate. This relationship results in a cyclical adjustment. In this sense, from the Thirlwall framework we develop a system that relates the dependence of southern country to the dynamics of the terms of trade, which is related to the quality of the productive structure.

Finally, learning and structural change are usually added to the BPCM by endogenizing income elasticities of imports and exports (Cimoli \& Porcile, 2014). In our expanded version of the BPCM, we follow a different approach, focusing on the price dynamics. The two perspectives are complementary, and a future research agenda should take into account both the effects of the productive structure on prices (terms of trade) and on quantities (income elasticities).

Finally, in order to have Prebisch and Thirlwall compatible, we need to think them in different terms. The PSH is a non-convergent model in which there is a secular decline on the terms of trade. A transition dynamics allows us to see the decline in the terms of trade only in the short-run, as our model maintains the long-run price-neutrality argument of the Thirlwall law. We suggest an intermediary medium-run in which the decline of the terms of trade is valid, even if it converges in the long-run, and at the same time the price effects are not neutral to the medium-run equilibrium growth rate. Then it is possible for both the PSH and the BPCM arguments to hold.

\section{Author Statement}

I would like to acknowledge Bart Verspagen for the helpful comments and interesting debates during the development of this article. I thank UNU-Merit and the CatChain project for the institutional and financial support. I also thank to two anonymous referees for the very relevant inputs that very much improved this manuscript, and the participants of the 22nd FMM conference (October 2018), in Berlin for the relevant discussions. I bear full responsibility for any eventual errors.

\section{Annex 1. Variable List}

\begin{tabular}{|c|c|c|c|}
\hline$Y_{i}$ & Total income & $\gamma_{0}$ & $\begin{array}{l}\text { Autonomous investment } \\
\text { parameter }\end{array}$ \\
\hline$K_{i}$ & Capital stock & $\gamma_{1}$ & $\begin{array}{l}\text { Sensitivity of investment to } \\
\text { capacity utilization }\end{array}$ \\
\hline$C_{i}$ & Total consumption & $\alpha$ & $\begin{array}{l}\text { Share of northern expenditure } \\
\text { on southern goods }\end{array}$ \\
\hline$S_{i}$ & Total savings & $\alpha_{0}$ & $\begin{array}{l}\text { Autonomous part of the share of } \\
\text { northern expenditure on } \\
\text { southern goods }\end{array}$ \\
\hline$I_{i}$ & Total investment & $\beta$ & $\begin{array}{l}\text { Share of southern expenditure } \\
\text { on northern goods }\end{array}$ \\
\hline$M_{i}$ & Total imports & $\beta_{0}$ & $\begin{array}{l}\text { Autonomous part of the share of } \\
\text { southern expenditure on } \\
\text { northern goods }\end{array}$ \\
\hline$X_{i}$ & Total exports & $g_{i}$ & Capital accumulation rate \\
\hline$P_{i}$ & Prices & $\theta_{i}$ & $\begin{array}{l}\text { Constants to the import/export } \\
\text { functions }\end{array}$ \\
\hline$P$ & Terms of trade & $\lambda_{i}$ & Labor productivity \\
\hline$L_{i}$ & Total employment & $G$ & Productivity gap \\
\hline$V_{i}$ & Real wages & $l_{i}$ & Employment rate \\
\hline$W_{i}$ & Nominal wages & $\rho$ & Catching-up parameter \\
\hline$F$ & Financial flows & $\beta_{i}$ & $\begin{array}{l}\text { Autonomous productivity } \\
\text { growth }\end{array}$ \\
\hline$\Lambda_{i}$ & Total workforce & $m$ & Constant growth of real wages \\
\hline$b_{i}$ & Fixed unit labor requirement & $n$ & $\begin{array}{l}\text { Real wage sensitivity to } \\
\text { southern labor }\end{array}$ \\
\hline$\varepsilon_{i}$ & Income elasticity of imports & $\xi$ & Terms of trade sensitivity \\
\hline$\mu_{i}$ & Price elasticity of imports & $\delta$ & Income elasticity of exports \\
\hline$a_{i}$ & Capital-output ratio & $v$ & Price elasticity of exports \\
\hline$s_{i}$ & Propensity to save & $\varphi$ & $\begin{array}{l}\text { Labor supply autonomous } \\
\text { growth }\end{array}$ \\
\hline$\omega_{i}$ & Wage share & $\psi$ & $\begin{array}{l}\text { Labor migration sensitivity to } \\
\text { wage share }\end{array}$ \\
\hline$\sigma_{i}$ & Profit share & & Subscripts: \\
\hline$u$ & Capacity utilization & $\mathrm{N}$ & Northern country \\
\hline$z$ & Markup & S & Southern country \\
\hline$E D$ & Excess demand & & \\
\hline
\end{tabular}


Annex 1. The Dutt (2002) model

A basic north-south model based on the Thirlwall law states that the relationship between growth rates depends on the ratio between income elasticity of imports in the north and the south.

$\widehat{Y_{S}} / \widehat{Y_{N}}=\varepsilon_{N} / \varepsilon_{S}$

The monopolistic north has its price level defined by a markup function over costs, with price-making firms:

$P_{N}=(1+z) W_{N} b_{N}$

In which $P_{N}$ is the price level in the north; $z$ consists in the mark-up $(z \geq 1)$; $W_{N}$ is the wage level in the north and $b_{N}$ is the fixed unit labor requirement for the northern good. An increase in markup and/or on costs raises price levels, as well as a reduction in labor productivity.

The south follows a perfect competition specification. Southern GDP $\left(Y_{S}\right)$ operates at full capacity. It follows a fixed the relationship between capital stock in the south $\left(K_{S}\right)$ and the fixed capital-output ratio in the south $\left(a_{S}\right)$.

$Y_{S}=K_{S} / a_{S}$

Real wages in the south $\left(V_{S}\right)$ is defined as the ratio between nominal wages $\left(W_{S}\right)$ and price index in the south $\left(P_{S}\right)$ :

$V_{S}=W_{S} / P_{S}$

Workers in the north consume all their income, while capitalists save a fraction $\left(s_{N}\right)$ of their income. The north spends a fraction $\alpha$ of their consumption expenditure on southern goods (and the rest on the northern goods). This fraction is equal to:

$\alpha=\alpha_{0} Y_{N}^{\varepsilon_{N}-1} P^{1-\mu_{N}}$

In which $\alpha_{0}$ is the autonomous part of the northern expenditure in southern goods; $Y_{N}$ the GDP in the north. Considering $E=1$, The terms of trade $(P)$ is given by the ratio between prices in the south $\left(P_{S}\right)$ and prices in the north $\left(P_{N}\right)$ :

$P=P_{S} / P_{N}$

In the south, workers spend all their income on southern goods. Southern capitalists save a fraction $\left(s_{S}\right)$ and consume the rest. Part of the consumption $(\beta)$ is spent on the northern good. Analogous to $\alpha ; \beta$ can be described as:

$\beta=\beta_{0}\left(\sigma_{S} Y_{S}\right)^{\varepsilon_{S}-1}(1 / P)^{1-\mu_{S}}$

$\beta_{0}$ is the autonomous part of the southern expenditure in northern goods. $\sigma_{S}$ is the profit share of southern total income. This profit share is the residual from the wage share $\left(\omega_{S}\right)$ on total output: $\omega_{S}=b_{S} V_{S}$. The profit share can be specified as the part of total income that does not go to wages:

$\sigma_{S}=\left(1-b_{S} V_{S}\right)$

In which $b_{S}$ is the labor-output ratio in the south $\left(b_{S}=L_{S} / Y_{S}\right)$.

The investment function follows a Kaleckian specification based on Bhaduri \& Marglin (1990), in which capacity utilization affects the capitalists perception of economic activity. When capacity utilization increases, capitalists perceive it as an increase in effective demand, which stimulates them to increase total capacity by immobilizing capital in order to sustain the increases in the demand. Investments in the north are then given by:

$g_{n}=I_{N} / K_{N}=\gamma_{0}+\gamma_{1}(u)$
$I_{N}$ is total investment in the north, $\gamma_{0}$ and $\gamma_{1}$ are positive constants. $u$ consists on the rate of capacity utilization, which is given by $u=Y_{N} / K_{N}$. The next step is to find explicit equations for northern and southern exports. Considering the equations for $P_{S}$ and $X_{S}$, the total value of southern exports is given by:

$P_{S} X_{S}=\alpha\left\{\left[1+\left(1-s_{N}\right) z\right] /(1+z)\right\} P_{N} Y_{N}$

Replacing $\alpha$ results in the reduced form:

$X_{S}=\theta_{S} P^{-\mu_{N}} Y_{N}^{\varepsilon_{N}}$

In which $\theta_{S}=\alpha_{0}\left[1+\left(1-s_{N}\right) z\right] /(1+z)$. $\theta_{S}$ is a constant.

The northern total exports to the south are equal to the southern imports from the north. Total southern imports are $M_{S}=$ $\beta \sigma_{S} Y_{S}$, then:

$P_{N} X_{N}=\beta \sigma_{S} P_{S} Y_{S}$

Expanding $\beta$ on the total northern exports equation, we have the reduced form:

$X_{N}=\theta_{N}(1 / P)^{-\mu_{S}} Y_{S}^{\varepsilon_{S}}$

In which the constant $\theta_{N}=\beta_{0} \sigma_{S}^{\varepsilon_{S}}$.

This simple static model highlights the properties of the northsouth interaction. Southern and northern exports are explicitly addressed in order to reach equilibrium in current account, balancing the values of exports in north and south.

\section{Dynamics properties of the Dutt model}

The dynamic properties of the Dutt (2002) model are derived from the excess demand $(E D)$ functions in the north and south. In the south:

$E D_{S}=C_{S S}+I_{S S}+X_{S}-Y_{S}$

As $M_{S}=C_{S S}+I_{S S}-Y_{S}$ and $M_{S}=\left(\frac{1}{P}\right) X_{N}$ :

$E D_{S}=X_{S}-\left(\frac{1}{P}\right) X_{N}$

Analogously, excess demand in the north $\left(E D_{N}\right)$ :

$E D_{N}=C_{N N}+I_{N}+X_{N}-Y_{N}$

$E D_{N}=I_{N}-S_{N}+X_{N}-P X_{S}$

Following a market clearing equilibrium, there is no excess demand in the long-run:

$E D_{i}=0$

When substituting all variables and applying the equilibrium conditions, we have the following static equations for terms of trade and capacity utilization $E D_{S}=X_{S}-\left(\frac{1}{P}\right) X_{N}=0$ :

$X_{N}=P X_{S}$

Substituting northern and southern exports:

$P=\left[\left(\theta_{S} / \theta_{N}\right)\left(u K_{N}\right)^{\varepsilon_{N}}\left(a_{S} / K_{S}\right)^{\varepsilon_{S}}\right]^{1 /\left(\mu_{N}+\mu_{S}-1\right)}$

From the Saving-Investment balance condition in the north $\left(I_{N}=S_{N}\right)$ :

$u=\gamma_{0} /\left[s_{N} \sigma_{N}-\gamma_{1}\right]$

In the long-run the capital stock grows according to the rates of capital accumulation in the two regions $\left(g_{i}=I_{i} / K_{i}\right)$. The short-run conditions are always satisfied $\left(E D_{i}=0\right)$. In this sense accumulation in the north is given by:

$g_{N}=\gamma_{0}+\gamma_{0} \gamma_{1} /\left[s_{N} \sigma_{N}-\gamma_{1}\right]$ 
In the south, savings determine investments. Only southern capitalists save. The savings function is then:

$S_{S}=S_{S} \sigma_{S} K_{S} / a_{S}$

The investment function given by the value of total savings in domestic currency:

$I_{S}=P^{\xi} S_{S}$

$\xi$ is a constant with positive value. As $I_{S}=S_{S}$ :

$g_{S}=s_{S} P^{\xi} \sigma_{S} / a_{S}$

Finally, terms of trade then fluctuate following the relationship between capital accumulation in the north and the south:

$\hat{P}=\left[1 /\left(\mu_{N}+\mu_{S}-1\right)\right]\left(\varepsilon_{N} g_{N}-\varepsilon_{S} g_{S}\right)$

Annex 2. Study of the signs of the Jacobian in the Steady State (Stability conditions)

Considering our jacobian matrix $(J)$ as:

$J=\left[\begin{array}{llll}a_{11} & a_{12} & a_{13} & a_{14} \\ a_{21} & a_{22} & a_{23} & a_{24} \\ a_{31} & a_{32} & a_{33} & a_{34} \\ a_{41} & a_{42} & a_{43} & a_{44}\end{array}\right]$

Then:

$a_{11}=-\frac{1}{\mu_{N}+\mu_{S}-1} \frac{\varepsilon_{S} S_{S} \sigma_{S}}{a_{S}} \xi P^{* \xi-1}$

a From the Marshall-Lerner condition, $\mu_{N}+\mu_{S}>1$. This implies $\frac{1}{\mu_{N}+\mu_{S}-1}>0$

b The relationship $\frac{\varepsilon_{S} S_{S} \sigma_{S}}{a_{S}}$ has $0<s_{S} \sigma_{S}<1$. Likely $a_{S}>\varepsilon_{S}>0$, then $0<\frac{\varepsilon_{S} S_{S} \sigma_{S}}{a_{S}}<1$.

c $\xi>0$ so the sign of $\xi P^{* \xi-1}$ depends on the sign of $P$ on the Steady State.

d Then $\operatorname{sign}\left(a_{11}\right)=-\operatorname{sign}\left(P^{*}\right)$.

$a_{12}=-\frac{1}{\mu_{N}+\mu_{S}-1} \frac{\varepsilon_{S} S_{S} P^{* \xi}}{a_{S}}$

Analogous to $a_{11}, \operatorname{sign}\left(a_{12}\right)=-\operatorname{sign}\left(P^{*}\right)$. Being $\operatorname{sign}(P)^{*}>0$, then $\operatorname{sign}\left(a_{12}\right)<0$.

$a_{13}=a_{14}=a_{21}=a_{22}=0$

$a_{23}=-n$

$n$ is always a positive, so $\operatorname{sign}\left(a_{23}\right)<0$

$a_{24}=\rho$

$\rho>0$, then $\operatorname{sign}\left(a_{24}\right)>0$

$a_{31}=\xi P^{* \xi-1} s_{S} \sigma_{S} \frac{1}{a_{S}}$

Analogously to the previous cases, $\operatorname{sign}\left(a_{31}\right)=\operatorname{sign}\left(P^{*}\right)$.

$a_{32}=P^{* \xi} s_{S} \frac{1}{a_{S}}-\psi$

The sign of $a_{32}$ depends on the relationship between $P^{*} \xi s_{S} \frac{1}{a_{S}}$ and $\psi$. Considering the condition $P^{* \xi} s_{S} \frac{1}{a_{S}}>\psi$ then $\operatorname{sign}\left(a_{32}\right)>0$

$a_{34}=a_{44}=-\rho$

As $\rho>0, \operatorname{Sign}\left(\mathrm{a}_{34}\right)=\operatorname{Sign}\left(\mathrm{a}_{44}\right)<0$

$a_{33}=a_{41}=a_{42}=a_{43}=0$
Table A1

Parameter variables.

\begin{tabular}{llllll}
\hline I. & $a_{S}$ & VIII. & $s_{s}$ & XV. & $\sigma_{N}$ \\
II. & $\xi$ & IX. & $b_{S}$ & XVI. & $\beta_{S}$ \\
III. & $\mu_{N}$ & X. & $b_{N}$ & XVII. & $\beta_{N}$ \\
IV. & $\mu_{S}$ & XI. & $\gamma_{0}$ & XVIII. & $\rho$ \\
V. & $\varepsilon_{S}$ & XII. & $\gamma_{1}$ & XIX. & $\psi$ \\
VI. & $\varepsilon_{N}$ & XIII. & $m$ & XX. & $\varphi$ \\
VII. & $s_{N}$ & XIV. & $n$ & & \\
\hline
\end{tabular}

Finally analyzing the sign of $P$ in the steady state $\left(P^{*}\right)$ :

$P^{*}=\left[\frac{\gamma_{0} a_{S} \psi}{\left[\varphi+\beta_{N}-\frac{\varepsilon_{N} \gamma_{0}}{\varepsilon_{S}}\left(1+\frac{\gamma_{1}}{s_{N} \sigma_{N}-\gamma_{1}}\right)\right]} \frac{\varepsilon_{N}}{\varepsilon_{S} s_{S}}\left(1+\frac{\gamma_{1}}{s_{N} \sigma_{N}-\gamma_{1}}\right)\right]^{1 / \xi}$

i $\gamma_{0} a_{S} \psi$ is a product of three positive numbers, as well as $\frac{\varepsilon_{N}}{\varepsilon_{S} s_{S}}$

ii As defined by Dutt (2002), the relationship between $s_{N} \sigma_{N}-$ $\gamma_{1}>0$ is a central condition for a converging trajectory dynamics, So $\left(1+\frac{\gamma_{1}}{s_{N} \sigma_{N}-\gamma_{1}}\right)>0$.

iii The relationship between $\left(\varphi+\beta_{N}\right)$ and $\left[\frac{\varepsilon_{N} \gamma_{0}}{\varepsilon_{S}}\left(1+\frac{\gamma_{1}}{s_{N} \sigma_{N}-\gamma_{1}}\right)\right]$ defines the final value of the sign. Defining $\left(\varphi+\beta_{N}\right)>$ $\left[\frac{\varepsilon_{N} \gamma_{0}}{\varepsilon_{S}}\left(1+\frac{\gamma_{1}}{s_{N} \sigma_{N}-\gamma_{1}}\right)\right]$ then $\operatorname{Sign}(P)>0$.

Considering $\operatorname{Sign}(P)>0$ and $P^{\xi} s_{S} \frac{1}{a_{S}}<\psi$, The Jacobian has the following signs:

$\operatorname{Sign}(J)=\left[\begin{array}{cccc}- & - & 0 & 0 \\ 0 & 0 & - & + \\ + & + & 0 & - \\ 0 & 0 & 0 & -\end{array}\right]$

Annex 3. Calibration procedure of the model

In this section we discuss the expected values for each parameter.

I We estimate the capital-output ratio using the Penn World Tables 9.0; then $2<a_{\mathrm{s}}<5$.

II Dutt (2002) states that the variable $\xi$ is smaller than 1 and bigger than 0 .

III Price elasticity of imports of the north and the south are usually considered small in the BPCM theory, what Blecker (2016) calls "elasticity pessimism". Considering them $n$ their absolute value, $\mu_{N}>0$ and $\mu_{S}>0$. We follow the Marshall-Lerner condition in which $\mu_{N}+\mu_{S}>1$, as argued by Dutt (2002).

IV The same as point III. $\mu_{N} \approx 1$ and $\mu_{S} \approx 1$

Table A2

Number of persons engaged (in dec.) divided by the output-sided real GDP at chained PPP. Selected countries.

\begin{tabular}{llllllll}
\hline Argentina & 0.28 & Mexico & 0.25 & Germany & 0.12 & Italy & 0.12 \\
Brazil & 0.34 & Canada & 0.11 & France & 0.11 & China & 0.48 \\
Colombia & 0.37 & USA & 0.09 & UK & 0.13 & India & 0.73 \\
\hline
\end{tabular}

Source: Penn World Tables 9.0

Table A3

Results for the parameter values.

\begin{tabular}{lll}
\hline $3<a_{s}<5$ & $0<s_{n}<1$ & $0<n<1$ \\
$0<\xi<1$ & $0<s_{S}<1$ & $0<\sigma_{N}<1$ \\
$\mu_{N} \approx 1$ & $0<b_{N}<b_{S}<1$ & $0<\beta_{S}<\beta_{N}<0.1$ \\
$\mu_{N}+\mu_{S}>1$ & $0<\gamma_{0}<1$ & $0<\rho<1$ \\
$0<\varepsilon_{S}<1$ & $\gamma_{1} \approx 0$ & $\varphi \approx 0$ \\
$0<\varepsilon_{N}<1$ or $\varepsilon_{N}>1$ & $0<m \leq 1$ & $0<\psi<1$ \\
\hline
\end{tabular}


$\mathrm{V}$ When $\varepsilon_{N}<1$, increases in northern income results in a lower proportion of expenditure in the southern good, so the southern good is income-inelastic. As increases in southern income will result in a higher proportion of expenditure in the northern good, $0<\varepsilon_{s}<1$.

VI The value of the income elasticity of import demand is always higher than zero $\left(\varepsilon_{N}>0\right)$. It is possible to consider two cases: (i) a higher income results in higher expenditure in the northern good $\left(0<\varepsilon_{N}<1\right)$. (ii) a higher income results in higher expenditure in the southern good $\left(\varepsilon_{N}>1\right)$.

VII $s_{N}$ consists in the fraction of income saved by capitalists, $0<s_{N}<1$.

VIII $0<s_{S}<1$.

IX From the model, $b_{S}=L_{S} / Y_{S}$. Using the PWT we can calculate these values from many countries using as $L_{S}$ the number of persons engaged, and as $Y_{S}$ the output-sided real GDP at chained PPP. $0<b_{S}<1$.

$\mathrm{X}$ As observed in point IX, developing countries have higher values for the labor-output ratio, so $0<b_{N}<b_{S}<1$.

XI $\gamma_{0}$ and $\gamma_{1}$ are positive constants, we consider $\gamma_{0}$ the animal spirit. It does not have an economic meaning in itself, but we consider its value between 0 (low confidence) and 1 (high confidence). $0<\gamma_{0}<1$.

XII $\gamma_{1}>0$ is the sensitivity of capacity utilization changes to the investment-capital ratio. This value is close to 0 , but positive. $\gamma_{1} \approx 0$.

XIII $m$ and $n$ are the effects on the southern real wage dynamics. $m$ is the constant rate of decrease in real wage growth. In this work we consider it having a small value (about $1 \%$ decrease maximum). So $0<m \leq 1$.

XIV $n$ is the elasticity of real wage to changes in the employment rate. It also has a value between 0 and 1 . $(0<n \leq 1)$

$\mathrm{XV}$ The constant profit rate of the north follows the range between zero (all income goes to wages) and one (all income goes to profits). So $0<\sigma_{N}<1$.

$\mathrm{XVI} \beta_{S}$ and $\beta_{N}$ are the exogenous positive parameters in the growth rate of labor productivity. The exogenous rate of technical change improvements is higher in the north than in the south: $\beta_{N}>\beta_{S}$.

XVII The exogenous growth of labor productivity $\left(\beta_{N}\right)$ is between 0 and 0.1 . So we have $0<\beta_{S}<\beta_{N}<0.1$.

XVIII $\rho$ is the effect of changes in the gap on the evolution of labor productivity in the south. Increases in $G$ also increases the productivity gap and have negative effects on the southern productivity. $\rho$ has a value between 0 and 1 . So $0<\rho<1$.

XIX $\varphi$ is the autonomous population growth. In developed countries it is very often negative while still positive in many developing countries. We will consider it having a positive value very close to zero $\varphi>0$ and $\varphi \approx 0$.

$\mathrm{XX} \psi$ is the elasticity of the labor supply to increases in the wage share. It has a positive number between zero and 1 . $(0<\psi<1)$

\section{References}

Alonso, J.A., Garcimartín, C., 1998. A New Approach to Balance-of-Payments Constraint: Some Empirical Evidence. Journal of Post Keynesian Economics 21, 259-282.

Barbosa-Filho, N.H., Taylor, L., 2006. Distributive and Demand Cycles in the Us Economy-A Structuralist Goodwin Model. Metroeconomica 57, 389-411.

Bhaduri, A., Marglin, S., 1990. Unemployment and the real wage: The economic basis for contesting political ideologies. Cambridge Journal of Economics 14, 375-393.

Blanchflower, D.G., Oswald, A.J., 1994. The Wage Curve. MIT Press.

Blecker, R.A., 2016. The debate over 'Thirlwall's law': Balance-of-payments-constrained growth reconsidered*. European Journal of Economics and Economic Policies: Intervention 13, 275-290.
Cimoli, M., Lima, G.T., Porcile, G., 2016. The production structure, exchange rate preferences and the short-run-Medium-run macrodynamics. Structural Change and Economic Dynamics 37, 13-26.

Cimoli, M., Porcile, G., 2010. Specialization, Wage Bargaining and Technology in a Multigoods Growth Model. Metroeconomica 61, 219-238.

Cimoli, M., Porcile, G., 2014. Technology, structural change and BOP-constrained growth: A structuralist toolbox. Cambridge Journal of Economics 38, 215-237.

Davidson, P. A, 1990. Post Keynesian Positive Contribution to "Theory. Journal of Post Keynesian Economics 13, 298-303.

Dávila-Fernández, M.J., Sordi, S., 2019. Distributive cycles and endogenous technical change in a BoPC growth model. Economic Modelling 77, 216-233.

Dosi, G., Sodini, M., Virgillito, M.E., 2015. Profit-driven and demand-driven investment growth and fluctuations in different accumulation regimes. Journal of Evolutionary Economics 25, 707-728.

Dutt, A.K., 2002. Thirlwall's Law and Uneven Development. Journal of Post Keynesian Economics 24, 367-390.

Dutt, A.K., 2019. Structuralists, Structures, and Economic Development. In: Nissanke, M., Ocampo, J.A. (Eds.), The Palgrave Handbook of Development Economics: Critical Reflections on Globalisation and Development. Springer International Publishing, Cham, pp. 109-141.

Englmann, F.C., 1994. A Schumpeterian model of endogenous innovation and growth. Journal of Evolutionary Economics 4, 227-241.

Fatás-Villafranca, F., Jarne, G., Sánchez-Chóliz, J., 2012. Innovation, cycles and growth. Journal of Evolutionary Economics 22, 207-233.

Foley, D.K., 2003. Endogenous technical change with externalities in a classical growth model. Journal of Economic Behavior \& Organization 52, 167-189.

Fu, X., Pietrobelli, C., Soete, L., 2011. The Role of Foreign Technology and Indigenous Innovation in the Emerging Economies: Technological Change and Catching-up. World Development 39, 1204-1212.

Gandolfo, G., 1971. Economic Dynamics: Methods and Models. Elsevier.

Goodwin, R.M., 1967. A Growth Cycle. In: Essays in Economic Dynamics. Palgrave Macmillan, London, pp. 165-170.

Harvey, D.I., Kellard, N.M., Madsen, J.B., Wohar, M.E., 2010. The Prebisch-Singer Hypothesis: Four Centuries of Evidence. The Review of Economics and Statistics 92, 367-377.

La Marca, M, 2010. Real Exchange Rate, Distribution and Macro Fluctuations in Export-Oriented Economies. Metroeconomica 61, 124-151.

Lavopa, A., Szirmai, A., 2018. Structural modernisation and development traps. An empirical approach. World Development 112, 59-73.

Lee, K., 2013. Schumpeterian analysis of economic catch-up: Knowledge, path-creation, and the middle-income trap. Cambridge University Press.

Lewis, W.A., 1954. Economic Development with Unlimited Supplies of Labour. The Manchester School 22, 139-191.

Liu, Z., Shen, J., Cai, S., Yan, F., 2018. MicroRNA Regulatory Network: Structure and Function. Springer.

Mccombie, J.S.L., 1989. 'Thirlwall's Law" and balance of payments constrained growth - a comment on the debate. Applied Economics 21, 611-629.

McCombie, J.S.L., Thirlwall, A.P., 1994. Economic Growth and the Balance-of-Payments Constraint. Palgrave Macmillan, LondonUK.

McCombie, J.S.L., Thirlwall, A.P., 1997. The Dynamic Harrod Foreign Trade Multiplier and the Demand-orientated Approach to Economic Growth: An Evaluation. International Review of Applied Economics 11, 5-26.

McCombie, J.S.L., 2012. Criticisms and Defences of the Balance of Payments Constrained Growth Model: Some Old, Some New. In: Soukiazis, E., Cerqueira, P.A. (Eds.), Models of Balance of Payments Constrained Growth: History, Theory and Empirical Evidence. Palgrave Macmillan, LondonUK, pp. 50-82.

Moreno-Brid, J.C., 2003. Capital Flows, Interest Payments and the Balance-ofPayments Constrained Growth Model: A Theoretical and Empirical Analysis. Metroeconomica 54, 346-365.

Nishi, H., 2019. Balance-of-payments-constrained cyclical growth with distributive class conflicts and productivity dynamics. Metroeconomica 70, 620-640.

Porcile, G. Spinola, D.S., 2018. Natural, Effective and BOP-Constrained Rates of Growth: Adjustment Mechanisms and Closure Equations. PSL Quarterly Review 71, 139-160.

Porcile, G., Yajima, G.T., 2019. New Structuralism and the balance-ofpayments constraint. Review of Keynesian Economics 7, 517-536.

Prebisch, R. 1950. The economic development of Latin America and its principal problems Naciones Unidas Comisión Económica para América Latina y el Caribe (CEPAL).

Pugno, M., 1998. The Stability of Thirlwall's Model of Economic Growth and the Balance-Of-Payments Constraint. Journal of Post Keynesian Economics 20, 559-581.

Razmi, A., 2016. Correctly analysing the balance-of-payments constraint on growth. Cambridge Journal of Economics 40, 1581-1608.

Sabot, R., 2019. Migration And The Labor Market In Developing Countries. Routledge.

Schumpeter, J. A. (1939). Business Cycles: A theoretical, historical and statistical analysis of the Capitalist process. Retrieved from http://libarch.nmu.org.ua/ handle/GenofondUA/20647

Shah, A., Desai, M., 1981. Growth Cycles with Induced Technical Change. The Economic Journal 91, 1006-1010.

Silverberg, G., Verspagen, B., 2003. Breaking the waves: A Poisson regression approach to Schumpeterian clustering of basic innovations. Cambridge Journal of Economics 27, 671-693.

Szirmai, A., 2015. Socio-Economic Development. Cambridge University Press.

Tavani, D., Zamparelli, L., 2017. Endogenous Technical Change in Alternative Theories of Growth and Distribution. Journal of Economic Surveys 31, 1272-1303. 
Thirlwall, A.P., 1979. The balance of payments constraint as an explanation of the international growth rate differences. PSL Quarterly Review 32.

Thirlwall, A.P., Hussain, M.N., 1982. The Balance of Payments Constraint. In: Capital Flows and Growth Rate Differences between Developing Countries, 34. Oxford Economic Papers, pp. 498-510.
Van der Ploeg, F., 1987. Growth cycles, induced technical change, and perpetual conflict over the distribution of income. Journal of Macroeconomics 9, 1-12.

Verspagen, B., 1992. Uneven growth between interdependent economies: An evolutionary view on technology gaps, trade and growth. Aldershot, Avebury. 